\title{
Evaluation of Creep Rupture Strength of High Nitrogen Ferritic Heat- Resistant Steels Using Small Punch Creep Testing Technique
}

\author{
Naveena ${ }^{\rrbracket}$ and Shin-ichi Komazaki ${ }^{\text {网 }}$ \\ ${ }^{\circledR}$ Division of Mechanical Engineering \\ Graduate School of Science and Engineering, Kagoshima University, Japan, 890-0065 \\ ${ }^{\circledR}$ Research Field in Engineering, Science and Engineering Area, \\ Research and Education Assembly, Kagoshima University, Japan, 890-0065
}

\begin{abstract}
The development of next generation ultra-heat-resistant ferritic steels for the future advanced thermal power plants which operate in excess of $700^{\circ} \mathrm{C}$ are currently in progress in Japan. The small punch (SP) creep testing technique which uses miniature specimens has been applied to evaluate creep rupture strength of newly developed high nitrogen ferritic steels. The SP creep tests have been carried out on different grades of high nitrogen ferritic steels in the temperature range of $600-800{ }^{\circ} \mathrm{C}$, under different loads in the range of 70-400 N, using specimens of dimension $\otimes 8 \mathrm{~mm} \times 0.5 \mathrm{~mm}$. The SP creep rupture results of high nitrogen ferritic steels have been compared with that of conventional steel (Gr.91). The high nitrogen steels exhibited higher creep rupture strength when compared to the Gr.91. The creep rupture results obtained from SP creep tests were correlated to the uniaxial creep rupture results obtained from conventional creep tests using a stress conversion coefficient of paper investigates the applicability of SP creep testing technique for the evaluation of creep rupture strength of high nitrogen ferritic heat-resistant steels.
\end{abstract}

${ }^{*}$ Corresponding author. Tel.: +81-99-285-8159; fax: +81-99-285-8245.

E-mail address: naveena@mech.kagoshima-u.ac.jp. 
Keywords: Small punch creep test, high nitrogen ferritic steels, heat-resistant steels, creep strength

\section{Introduction}

High chromium ferritic heat-resistant steels have been widely employed as structural materials for high temperature components of fossil-fired power plants because of their superior high temperature strength, high thermal conductivity and low thermal expansion coefficient. The present generation high chromium ferritic heat-resistant steels such as Gr.91, Gr.92 and Gr.122 are employed for components operating in the service temperature range of $550-620{ }^{\circ} \mathrm{C}[1,2]$. From the view point of fuel conservation, energy saving and reduction of $\mathrm{CO}_{2}$ emission, there is a world-wide demand for enhancing thermal efficiency of fossil-fired power plants that can be effectively achieved by increasing their steam temperature above $600{ }^{\circ} \mathrm{C}$ and pressure above $30 \mathrm{MPa}[3,4]$. These elevated steam conditions impose stringent requirements on mechanical properties of structural materials, more importantly, on their creep strength. Significant efforts are being made world-wide to develop heat-resistant steels for such applications [4-8]. In Japan, research and development of next generation ferritic heat-resistant steels using nitrogen as a potential alloying element is currently in progress for applications in future advanced thermal power plants whose operating temperature is above $700{ }^{\circ} \mathrm{C}$ [9]. The aim is to achieve $100,000 \mathrm{~h}$ target strength at $100 \mathrm{MPa}$ at $700{ }^{\circ} \mathrm{C}$ in these heat-resistant steels.

Creep properties of different grades of these newly developed high nitrogen ferritic steels are being evaluated using the conventional uniaxial creep test. As the conventional tests necessitate a large amount of material for preparation of creep test specimen, to make effective use of the material available for testing and to assist in the design and development of these high nitrogen ferritic steels, the small punch (SP) creep testing technique has been applied to evaluate their creep rupture strength. In the SP creep test, a small disc type specimen, having diameter in the range of 3-10 $\mathrm{mm}$ and thickness in the range of $0.25-0.5$ $\mathrm{mm}$, is loaded at high temperature using a ceramic ball indenter of diameter in the range of 1$2.5 \mathrm{~mm}$, under constant applied load, till the specimen ruptures. The rupture time determined from SP creep tests can be correlated to the rupture time obtained from uniaxial creep tests using SP load-uniaxial stress conversion coefficient. The SP creep testing technique was employed for various applications such as creep rupture strength evaluation of welded joints, remaining life assessment of in-service components, for optimizing chemical compositions in 
alloy development etc. [10-12]. The paper discusses creep behavior of newly developed high nitrogen ferritic heat-resistant steels investigated using SP creep testing technique. The study investigates the applicability and usefulness of this technique in the development of high nitrogen ferritic heat-resistant steels.

\section{Experimental Procedure}

\subsection{Materials}

The study involved three newly developed high nitrogen ferritic steels which are designated as HN9, HN9L and HN10 and a conventional Gr.91 steel [13]. The chemical compositions and heat treatment conditions of the high nitrogen ferritic steels are given in Table1. The high nitrogen ferritic steels were produced by pressurized electro-slag remelting (PESR) method. The microstructural studies of the high nitrogen ferritic steels were carried out using field emission scanning electron microscope (FE-SEM). The energy dispersive X-ray spectrometry (EDX) in conjunction with FE-SEM was used to identify the precipitates in the steels.

\subsection{Creep tests}

The specimens for SP creep tests were prepared by machining $8 \mathrm{~mm}$ diameter rods from the heat treated rectangular bars, which were subsequently cut into slices of thickness approximately $0.8 \mathrm{~mm}$. Both sides of the specimens were ground to a thickness of $0.5 \mathrm{~mm}$ with a thickness tolerance of $\pm 0.005 \mathrm{~mm}$. The specimen surfaces were finally polished using $0.3 \mu \mathrm{m} \mathrm{Al}{ }_{2} \mathrm{O}_{3}$ solution. The $\mathrm{SP}$ creep tests were carried out at various temperatures in the range of $600-800{ }^{\circ} \mathrm{C}$, under different loads in the range of $70-400 \mathrm{~N}$. The SP creep testing machine employed in this study is shown in Fig.1a. A schematic of specimen-indenter assembly inside the furnace is shown in Fig.1b. The specimen was clamped between the upper and lower dies, and was loaded through a $\mathrm{Si}_{3} \mathrm{~N}_{4}$ spherical ball indenter of diameter $2.38 \mathrm{~mm}$. In order to prevent severe oxidation of the specimen, the tests were carried out in high purity argon gas atmosphere. The specimen temperature was maintained constant with an accuracy of $\pm 1{ }^{\circ} \mathrm{C}$. The conventional uniaxial creep rupture tests were conducted in the stress range of $60-180 \mathrm{MPa}$, at 650 and $700{ }^{\circ} \mathrm{C}$.

\section{Results and discussion}

\subsection{Microstructures of steels prior to creep test}


Figures 2a-c show the back-scattered electron micrographs which depict the microstructures of HN9, HN9L and HN10, respectively, after the heat treatment. The microstructures of HN9 and HN9L consisted of tempered martensite lath structure and few percent ferrite (about 5 vol. \%). The steels contained vanadium and chromium rich nitrides distributed throughout the matrix. The tungsten rich Laves phase $\left(\mathrm{Fe}_{2} \mathrm{~W}\right)$ was precipitated along the boundaries and within grains. The microstructure of HN10 consisted of fully ferrite structure with vanadium and chromium rich nitrides distributed in the matrix. No Laves phase was precipitated in this steel. Figures 3a-d show the EDX spectrum of the Laves phase (HN9L), vanadium nitride (HN10), chromium nitride (HN10) and the matrix (HN10).

\subsection{SP creep deformation and rupture behavior}

Figures 4a-c show the SP creep curves (variation of central deflection with time) measured on HN9, HN9L and HN10, respectively. At all the temperatures and loads, the SP creep curves exhibited distinct primary, secondary and tertiary creep regions as generally observed in standard uniaxial creep curves. A relatively large instantaneous deflection after the application of load was exhibited in the SP creep tests unlike in uniaxial creep tests where a large instantaneous elongation is not generally observed. This characteristic of the SP creep test is attributed to the initial plastic bending deformation of the specimen. After the application of load, the specimen experiences an instantaneous high stress due to small initial contact area between the specimen and indenter. This instantaneous high stress acting on the specimen causes higher plastic deformation and thereby large bending deflection. Figures 5ac show the central deflection rate versus time curves obtained on different high nitrogen steels at different temperatures and loads. The primary creep region was characterized by a deflection rate decreasing steeply with time. The decrease in deflection rate continued till a secondary creep region was attained. In the secondary creep region, the deflection rate reached a minimum value. The tertiary creep region was characterized by an accelerating deflection rate with subsequent rupture of the specimen. The central deflection at rupture was approximately constant $(2.5 \mathrm{~mm})$ regardless of the test load and the time to rupture in all the three steels. During the initial stage of deformation, the specimen-indenter contact area increases rapidly and the bending process acts as a dominant deformation process. Following this, the membrane stretching mode of deformation dominates in the secondary creep stage where the contact area is controlled by the reduction in thickness. In the tertiary region, localized deformation occurs with simultaneous initiation and propagation of cracks which leads to rapid increase of deflection rate and final rupture of the specimen. Figures 5a-c 
compare the creep deformation behavior of high nitrogen steels at each different load and temperature. There was no significant difference in the SP creep deformation behavior among these high nitrogen steels.

Figure $6 \mathrm{a}$ shows the ruptured specimen of HN9L, tested at $725^{\circ} \mathrm{C}$ at $140 \mathrm{~N}$. The rupture occurred at a distance away from the centre of specimen along the circumference which indicates that the maximum stress/strain occurs not at the centre of the specimen but at a distance away from the centre along the circumference. Figure $6 \mathrm{~b}$ shows the fracture surface of the ruptured specimen HN9L, tested at $725{ }^{\circ} \mathrm{C}$ at $140 \mathrm{~N}$. A dimple rupture morphology which is a typical characteristic of ductile transgranular fracture was detected. Similar mode of fracture was observed in the other high nitrogen steels also.

The relationship between the minimum deflection rate and the time to rupture was analyzed in these steels. Figure 7 shows the log-log plot of minimum deflection rate versus time to rupture in the Gr.91 [13] and high nitrogen steels. The relationship between the minimum deflection rate and time to rupture obeyed the Monkman-Grant relationship which is widely applicable to conventional creep test results between minimum creep rate and time to rupture. The minimum deflection rate was found to be well correlated with the creep rupture time with a slope of 0.98 , which is close to 1 for many metallic materials. The significance of this relationship is that one can predict creep rupture time in any SP creep test when its minimum deflection rate is attained. This is mainly useful in SP creep tests carried out at lower loads where the specimen takes longer time to rupture. This relationship is also useful to ensure the reliability of SP creep tests. The applicability of Monkman-Grant relationship to SP creep testing was studied in detail by Dobeš and Milička [14] and was also reported by other researchers [11, 15-17].

\subsection{Creep rupture strength of high nitrogen steels}

The Larson-Miller parametric method is one of the most commonly used extrapolation techniques for predicting $100,000 \mathrm{~h}$ creep rupture strength from shorter rupture time data in conventional creep test. The Larson-Miller equation can be expressed as,

$P=T\left(\log _{r}+C\right) / 1000$

where $P$ is the Larson-Miller parameter, $T$ is the test temperature in $\mathrm{K}, t_{r}$ is the time to rupture in hours and $C$ is a constant referred to as Larson-Miller constant. The SP creep rupture data of high nitrogen ferritic steels was analyzed by means of Larson-Miller parameter. The Larson-Miller constant for the present analysis was considered as 20. The Larson-miller 
constant of 20 was reported to be suitable for the base materials [18-20] and the welded joints [1] of high chromium ferritic steels. Figure 8 shows the SP creep rupture test results of high nitrogen steels and Gr.91 steel [13]. The graph compares the creep rupture strength of high nitrogen ferritic steels and the Gr.91 steel. The high nitrogen ferritic steels exhibited higher creep rupture strength than the Gr.91 steel. There was no significant difference in creep rupture strengths among the high nitrogen ferritic steels. Among the high nitrogen ferritic steels, the HN9 and HN9L had same chemical composition but different heat treatment conditions. The HN9L was tempered at $700{ }^{\circ} \mathrm{C}$ for longer duration of $45 \mathrm{~h}$ while the $\mathrm{HN} 9$ was tempered at relatively higher temperature of $780{ }^{\circ} \mathrm{C}$ for a shorter time of $1 \mathrm{~h}$. Therefore, it should be noted here that the different tempering conditions given to the high nitrogen steels (HN9 and HN9L) had only a marginal effect on the creep rupture strength of these steels. Further, the steel HN10 which had ferrite structure also showed similar creep rupture strength as that of HN9 and HN9L which had tempered martensite lath structure. These results clearly indicate that a considerable creep strength can be achieved even in the fully ferrite matrix, by suitably optimizing the chemical composition, heat treatment condition and type of precipitates in the high nitrogen ferritic steel.

The microstructural evolution occurred during creep deformation of HN9, HN9L and HN10 was examined. Figures 9a-c show the microstructures of HN9, HN9L and HN10 after the creep test, up to $933 \mathrm{~h}$ at $775^{\circ} \mathrm{C}$ at $80 \mathrm{~N}, 987 \mathrm{~h}$ at $775^{\circ} \mathrm{C}$ at $80 \mathrm{~N}$ and $1152 \mathrm{~h}$ at $725{ }^{\circ} \mathrm{C}$ at $140 \mathrm{~N}$, respectively. In the case of HN9 and HN9L, coarsening of Laves phase progressed with the creep deformation. In the steel HN10, significant amount of Laves phase precipitation occurred along the prior austenite grain boundaries as well as within the grains. The vanadium nitride and chromium nitride precipitates were found to be retained in all the high nitrogen steels during creep deformation. The improved creep rupture strength of the high nitrogen steels can be attributable primarily to the precipitation strengthening (particle hardening) resulting from vanadium nitride, chromium nitride and Laves phase and solid solution strengthening (solution hardening) due to tungsten and molybdenum. In the present high nitrogen steels, the nitrogen and vanadium contents were considerably higher than those in the Gr.91 steel. Addition of nitrogen to high chromium ferritic steels generally increases the formation of vanadium nitride [21]. The studies have shown that the minimum creep rate of $\alpha$ iron could be greatly reduced by introducing MX particles into the Fe- $\mathrm{VNbC}$ steels [22]. The MX particles act as obstacles to dislocation motion and slower the recovery of dislocation substructure. The distribution of vanadium and chromium nitrides in the matrix 
and along the lath, block and prior austenite grain boundaries can cause pinning of the boundary migration during creep deformation. The pinning effect could result in retardation of the onset of tertiary creep stage and increase of the time to rupture. Taneike et al. [23] investigated creep rupture strength of $9 \mathrm{Cr}-\mathrm{Mo}-\mathrm{V}-\mathrm{Nb}-\mathrm{W}-\mathrm{N}$ martensitic steel dispersed with nanometer sized vanadium and niobium rich carbonitride particles in the matrix and along the lath, block, packet and prior austenite boundaries. The higher volume fraction of carbonitride particles than that of $\mathrm{M}_{23} \mathrm{C}_{6}$ particles which resulted in decrease of inter-particle distance was reported to significantly increase the pinning force for migration of lath and block boundaries during creep deformation. As a consequence, the onset of tertiary creep stage was retarded which increased the time to rupture [23]. Furthermore, their study on the influence of carbon concentration on the creep rupture lives of different $9 \mathrm{Cr}-\mathrm{Mo}-\mathrm{V}-\mathrm{Nb}-\mathrm{W}-\mathrm{N}$ steels showed a significant decrease of minimum creep rate and increase of time to rupture with decreasing carbon concentration (carbon less than 0.05 wt.\%) [23]. The lower carbon concentration in such steels promotes the formation of MX type nitrides/carbonitrides much before the formation of $\mathrm{M}_{23} \mathrm{C}_{6}$ as the vanadium and niobium are strong nitride/carbonitride forming elements. The present high nitrogen steels contained extremely low carbon which is about 0.01 wt.\%. In addition, these high nitrogen steels contained significant amount of tungsten. The beneficial effect of tungsten in improving creep strength of high chromium steels has been reported previously [22]. The solid solution hardening due to tungsten and/or molybdenum was found to be effective even if the precipitation strengthening was absent in the steel [22]. Misosaku et al. [24] studied the creep rupture strength of austenitic heat resistant steels in which they induced $\mathrm{Fe}_{2} \mathrm{Nb}$ Laves phase on the grain boundaries. Their study showed that the precipitation of stable $\mathrm{Fe}_{2} \mathrm{Nb}$ Laves phase on the grain boundaries could increase the creep rupture life of the steel significantly. The grain boundary precipitation strengthening was reported to be a key mechanism to improve the creep rupture strength in those heat-resistant steels. The similar strengthening mechanism might also be contributing to the higher creep rupture strength of the present high nitrogen steels. All the above discussed mechanisms are expected to have contributed for the improved creep rupture strength of the present high nitrogen ferritic steels. However, detailed studies are currently underway to elucidate the mechanism of creep strengthening in these high nitrogen ferritic steels.

\subsection{Equivalence between SP and uniaxial creep rupture results}


In order to determine equivalent uniaxial creep rupture results from the SP creep rupture results, it is essential to convert the SP creep load $(F)$ to stress $(\sigma)$ in uniaxial creep test which gives the same rupture time, using a conversion coefficient. The relationship between SP load and uniaxial stress can be written as,

$F=\alpha \sigma$

where $\alpha$ is a conversion coefficient. The conversion coefficient depends on the material properties and geometrical parameters [25]. Komazaki et al. [13] performed the finite element analyses to study the correlation between the SP and uniaxial creep rupture results in the Gr.91 steel. The conversion coefficient was determined to be 2.05. In this study, the correlation between the SP creep rupture results and uniaxial creep rupture results was analyzed using $\alpha=2.05$. Figures $10 \mathrm{a}-\mathrm{d}$ show the stress versus time to rupture curves of the high nitrogen steels and the Gr.91 steel [13], comparing the SP and uniaxial creep test results correlated using $\alpha=2.05$. A relatively good agreement between the SP and uniaxial creep rupture results was obtained. It should be noted here that the number of creep data available for this plot are limited as the other SP creep tests were conducted at higher test temperatures. Therefore, to analyze the SP creep rupture data obtained at different temperatures, the Larson-Miller parametric method was used. Figures 11a-d show the comparison of SP and uniaxial creep rupture results, where the stress is plotted against the Larson-Miller parameter $(\mathrm{C}=20)$ on a semi-logarithmic scale, for the high nitrogen steels and Gr.91 steel [13]. The SP and uniaxial creep rupture results were found to be in relatively good agreement. Hence, the conversion coefficient of 2.05 can be used for obtaining the equivalent uniaxial creep rupture results from the SP creep rupture results for the high nitrogen ferritic steels also.

\section{Conclusions}

The SP creep testing technique was applied for evaluating the creep rupture strength of newly developed high nitrogen ferritic heat-resistant steels. The SP creep tests were conducted on different grades of high nitrogen ferritic heat-resistant steels over wide range of loads and temperatures using $\varnothing 8 \mathrm{~mm} \times 0.5 \mathrm{~mm}$ specimens. The creep rupture strength of high nitrogen ferritic steels was higher than that of the Gr.91 steel. There was no significant difference in the creep rupture strengths among the high nitrogen ferritic steels. The creep rupture strength of the high nitrogen steel having fully ferrite matrix was as high as that of the steels having tempered martensitic microstructure. The SP creep rupture test results of high nitrogen 
ferritic steels could be correlated to the corresponding uniaxial creep rupture test results using the conversion coefficient of 2.05. The investigation confirms the applicability of SP creep testing technique, as a potential miniature specimen testing technique, for evaluating the creep rupture strength of the high nitrogen ferritic heat-resistant steels.

\section{Acknowledgments}

This work was carried out as part of the research activities of ALCA (Advanced Low Carbon Technology Research and Development Program). The financial support received from JST (Japan Science and Technology Agency) is greatly acknowledged. Authors also acknowledge the support and encouragement received from the Head and members of this project.

\section{References}

[1] F. Masuyama, Creep rupture life and design factors for high-strength ferritic steels, Int. J. Press. Vessel. Piping. 84 (2007) 53-61.

[2] R. Viswanathan and W. Bekker, Materials for ultra supercritical coal power plantsBoiler materials: Part 1, J. Mater. Eng. Perform. 10 (1) (2001) 81-95.

[3] M. Fukuda, E. Saito, H. Semba, J. Iwasaki, S. Izumi, S. Takano, T. Takahashi and Y. Sumiyoshi, Advanced USC technology development in Japan, in:D. Gandy, J. Shingledecker (Eds.), Advances in Materials Technology for Fossil Power PlantsProceedings from the Seventh International Conference, ASM International (2013) 24-40.

[4] F. Masuyama, History of power plants and progress in heat resistant steels, The Iron. Steel Inst. Japan. Int. 41(2001) 612-625.

[5] R. Sun, Z. Cui and Y. Tao, Progress of China $700{ }^{\circ} \mathrm{C}$ USC development program, in:D. Gandy, J. Shingledecker (Eds.), Advances in Materials Technology for Fossil Power Plants-Proceedings from the Seventh International Conference, ASM International (2013) 1-8.

[6] A. D. Gianfrancesco, A. Tizzanini and M. Jedamzik, ENCIO project: An European approach to $700^{\circ} \mathrm{C}$ power plant, in:D. Gandy, J. Shingledecker (Eds.), Advances in Materials Technology for Fossil Power Plants-Proceedings from the Seventh International Conference, ASM International (2013) 9-23.

[7] J. Shingledecker, R. Purgert and P. Rawls, Current status of the U.S DOE/OCDO AUSC materials technology research and development program, in:D. Gandy, J. Shingledecker (Eds.), Advances in Materials Technology for Fossil Power Plants- 
Proceedings from the Seventh International Conference, ASM International (2013) 41-52.

[8] A. Mathur, O.P. Butani, T. Jayakumar, D. K. Dubey and S.C. Chetal, India's national A-USC mission-plan and progress, in:D. Gandy, J. Shingledecker (Eds.), Advances in Materials Technology for Fossil Power Plants-Proceedings from the Seventh International Conference, ASM International (2013) 53-59.

[9] H. Nakashima, S. Yamazaki and M. Mitsuhara, Development of high nitrogen ferritic heat-resistant steel for boiler material in next generation power plant, CAMP-ISIJ Meeting, 28 (2015) 867.

[10] J. D. Parker and J. D James, Creep behavior of miniature disc specimens of low alloy steel, Int. Conf. on Developments in Progressing Technology, ASME, 279 (1994) 167172.

[11] M. D. Mathew, J. Ganesh Kumar, V. Ganesan and K. Laha, Small punch creep studies for optimization of nitrogen content in $316 \mathrm{LN}$ SS for enhanced creep resistance, Metall. Mater. Tran. A.45 (2014) 731-737.

[12] S. Komazaki, T. Kato, Y. Kohno and H. Tanigawa, Creep property measurements of welded joint of reduced-activation ferritic steel by the small punch creep test, Mater. Sci. Eng. A 510-511 (2009) 229-233.

[13] S. Komazaki, T. Tokunaga and Y. Kawaji, Small punch creep property of high Cr ferritic steels, in: K. Matocha, R. Hurst, W. Sun (Eds.), Proc. $3^{\text {rd }}$ Inter. conf. of SSTT (2014) 312-318.

[14] F. Dobeš and K. Milička, On the Monkman-Grant relation for small punch test data, Mater. Sci. Eng. A 336 (2002) 245-248.

[15] S. Komazaki, T. Nakata, T. Sugimoto and Y. Kohno, Relationship between small punch creep properties and uniaxial creep properties of chromium martensitic steels, in: B. Raj (Ed.), "Advances in stainless steel", Universities Press; Boca Raton (2009) 135145.

[16] Y. Suzuki and Y. Nakatani, Creep property evaluation of $10 \mathrm{CrMoVNbN}$ casting steels by using SP creep test methods, in: K. Matocha, R. Hurst, W. Sun (Eds.), Proc. $3^{\text {rd }}$ Inter. conf. of SSTT (2014)293-299.

[17] J. Ganesh Kumar and K. Laha, Mater. Sci. Eng. A 641 (2015) 315-322. 
[18] K. Kimura, H. Kushima, K. Yagi and C. Tanaka, In: Proc. of the $7^{\text {th }}$ JIM International symposium on aspects of high temperature deformation and fracture in crystalline materials, The Japan Institute of Metals; Hosoi et al. (Eds) (1993) 309-316.

[19] K. Kimura, H. Kushima, F. Abe and K. Yagi, In: Creep resistant metallic materials. J. Purmensky (Ed). Ostrava: Vitokovice a.s.; 1996. p. 286-295.

[20] K. Kimura, Y. Toda, H. Kushima and K. Sawada, International Journal of Pressure Vessels and Piping, 87 (2010) 282.

[21] A. Iseda, H. Teranishi and F. Masuyama, The Iron. Steel Inst. Japan. Inter. 76 (1990) 7.

[22] K. Maruyama, K. Sawada and J. Koike, Strengthening mechanisms of creep resistant tempered martensitic steel, ISIS Inter. 41 (2001) 641-653.

[23] M. Taneike, F. Abe and K. Sawada, Creep-strengthening of steel at high temperatures using nano-sized carbonitride dispersions, Nature, 424 (2003) 294-296.

[24] Y. Misosaku, I. Tarigan, N. Takata, M Ueda, T. Maruyama and M. Takeyama, Creep of novel austenitic heat-resistant steel of $\mathrm{Fe}-20 \mathrm{Cr}-30 \mathrm{Ni}-2 \mathrm{Nb}$ under steam atmosphere at 1073 K, in: D. Gandy, J. Shingledecker (Eds.), Advances in Materials Technology for Fossil Power Plants-Proceedings from the Seventh International Conference, ASM International (2013) 1352-1362.

[25] F. Dobeš and K. Milička, Comparison of conventional and small punch creep tests of mechanically alloyed Al-C-O alloys, Mater. Character. 59(7) (2008) 961-964.

Table 1.Chemical compositions and heat treatment conditions of high nitrogen ferritic steels.

\begin{tabular}{lllllllllllll}
\hline & \multicolumn{10}{c}{ Chemical composition (wt. \%) } \\
\cline { 2 - 13 } Steel & $\mathrm{C}$ & $\mathrm{N}$ & $\mathrm{Cr}$ & $\mathrm{Mo}$ & $\mathrm{V}$ & $\mathrm{Nb}$ & $\mathrm{W}$ & $\mathrm{Co}$ & $\mathrm{Mn}$ & $\mathrm{Ni}$ & $\mathrm{Si}$ & $\mathrm{Fe}$ \\
\hline HN9/9L & 0.01 & 0.32 & 9.06 & 1.04 & 0.6 & 0.02 & 5.97 & 4.0 & 0.07 & 0.01 & 0.06 & balance \\
HN10 & 0.015 & 0.34 & 15.0 & 1.0 & 1.3 & 0.02 & 6.0 & 4.0 & 0.07 & 0.01 & 0.06 & balance \\
\hline
\end{tabular}

HN9: $1200{ }^{\circ} \mathrm{C}-30 \mathrm{~min}$ (air cooling) $+780^{\circ} \mathrm{C}-1 \mathrm{~h}$ (water quenching) HN9L: $1200^{\circ} \mathrm{C}-30 \mathrm{~min}$ (air cooling) $+700^{\circ} \mathrm{C}-45 \mathrm{~h}$ (water quenching) HN10: $1200^{\circ} \mathrm{C}-30$ min (air cooling) 


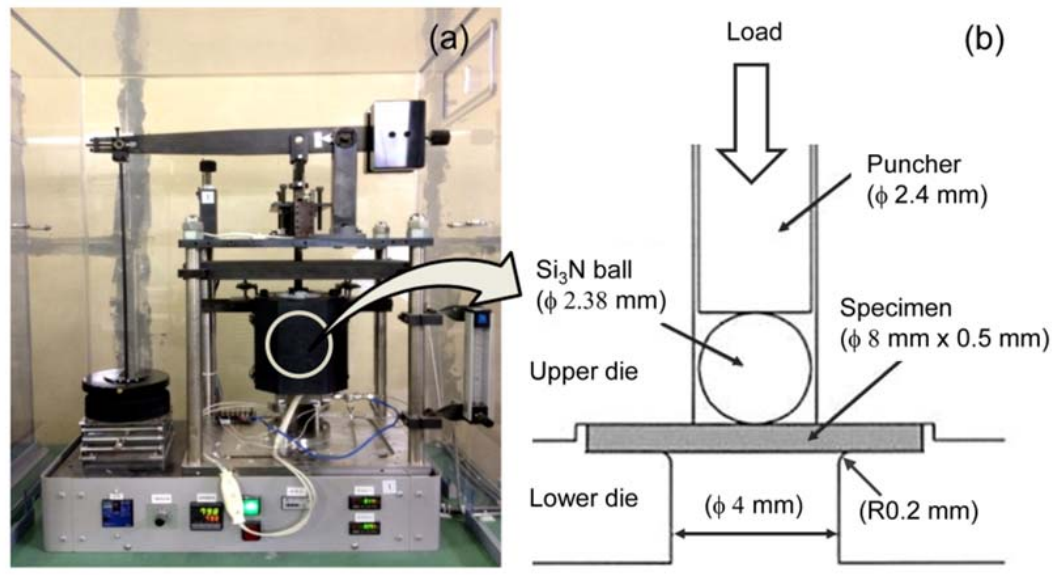

Fig. 1. a) SP creep testing machine and b) schematic of specimen-indenter assembly inside furnace.
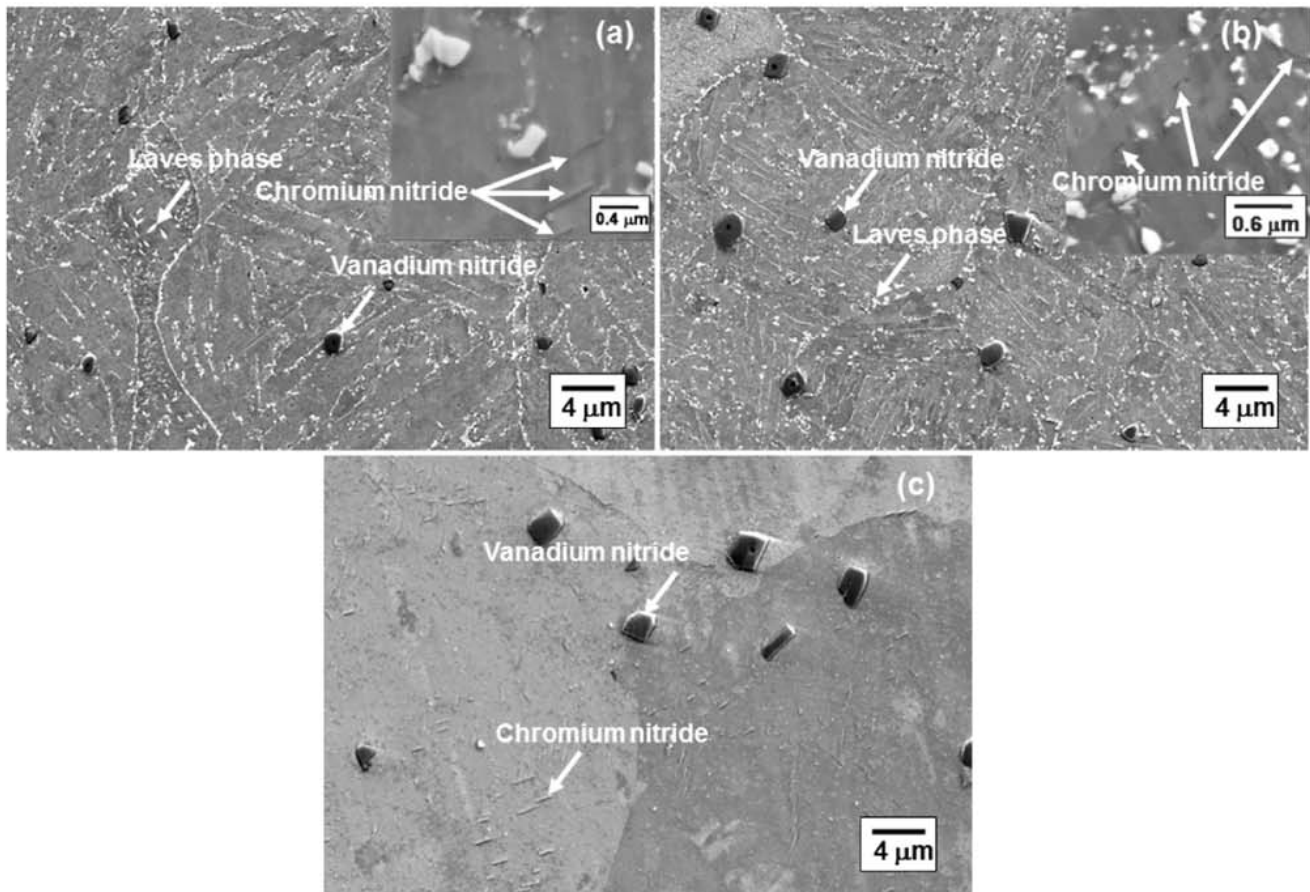

Fig. 2 Back-scattered electron micrographs of a) HN9, b) HN9L and c) HN10 depicting the microstructures after heat treatment. 

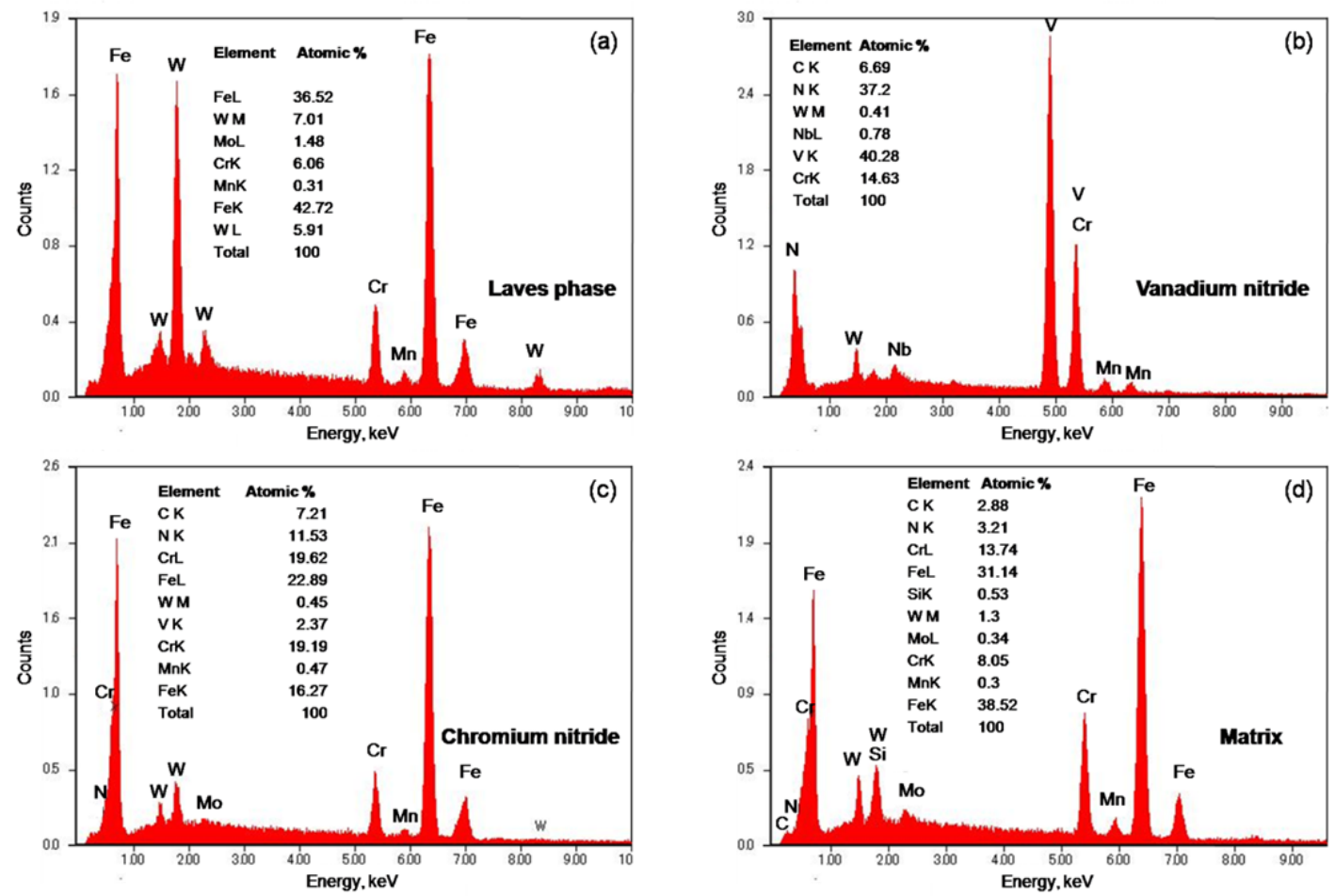

Fig. 3 Energy dispersive X-ray spectrum of a) Laves phase (HN9L), b) vanadium nitride (HN10) and c) chromium nitride (HN10) and d) matrix (HN10). 

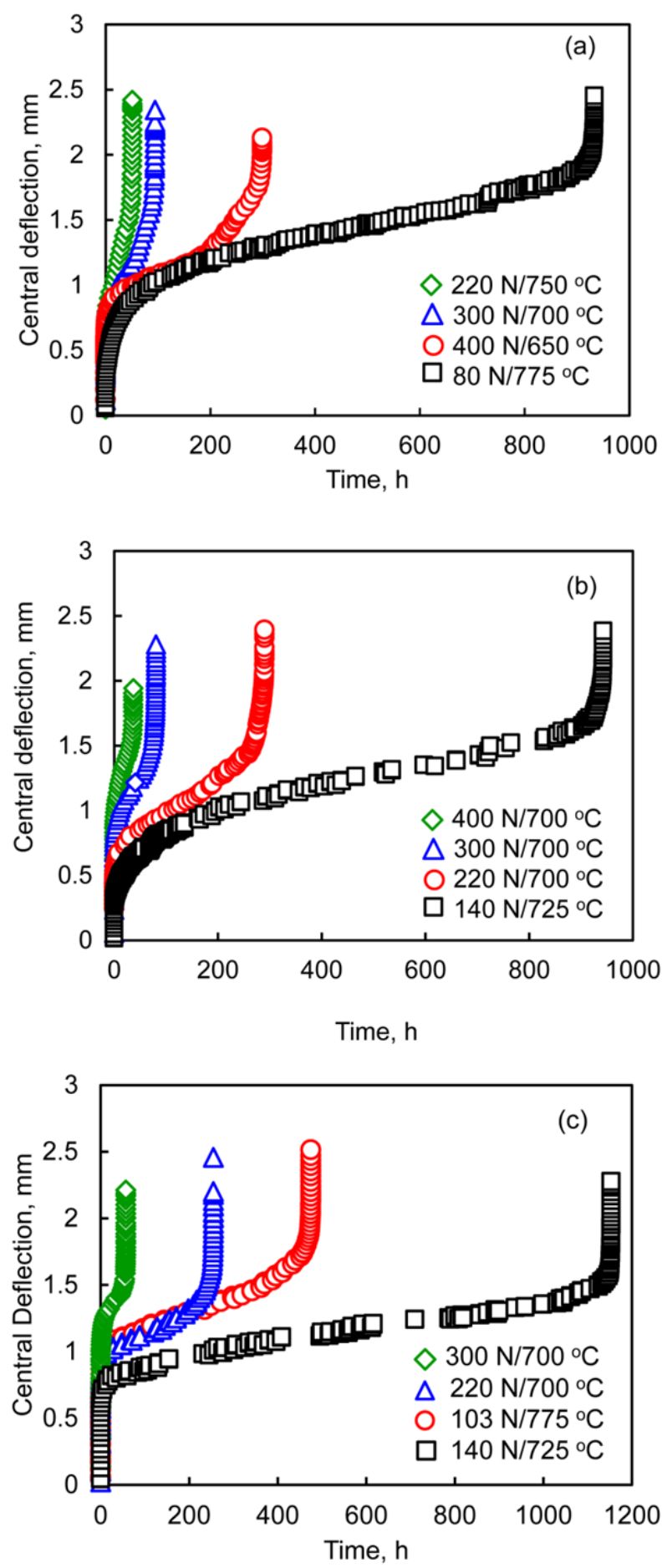

Fig. 4 Typical SP creep curves measured on a) HN9, b) HN9L and c) HN10 at various temperatures and loads. 

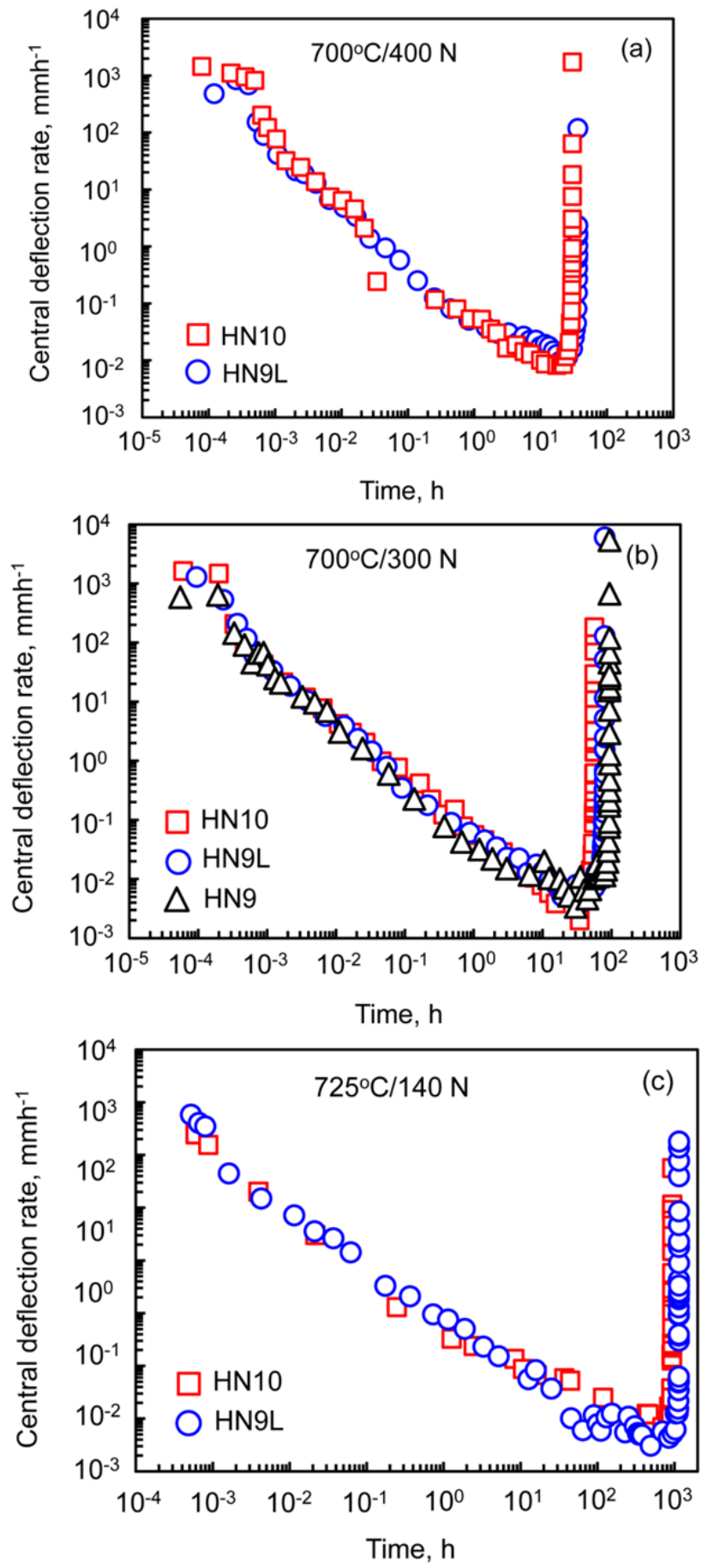

Fig. 5 Comparison of creep deformation behavior of different high nitrogen steels at a) 700 $\left.{ }^{\circ} \mathrm{C}, 400 \mathrm{~N}, \mathrm{~b}\right) 700{ }^{\circ} \mathrm{C}, 300 \mathrm{~N}$ and c) $725^{\circ} \mathrm{C}, 140 \mathrm{~N}$. 

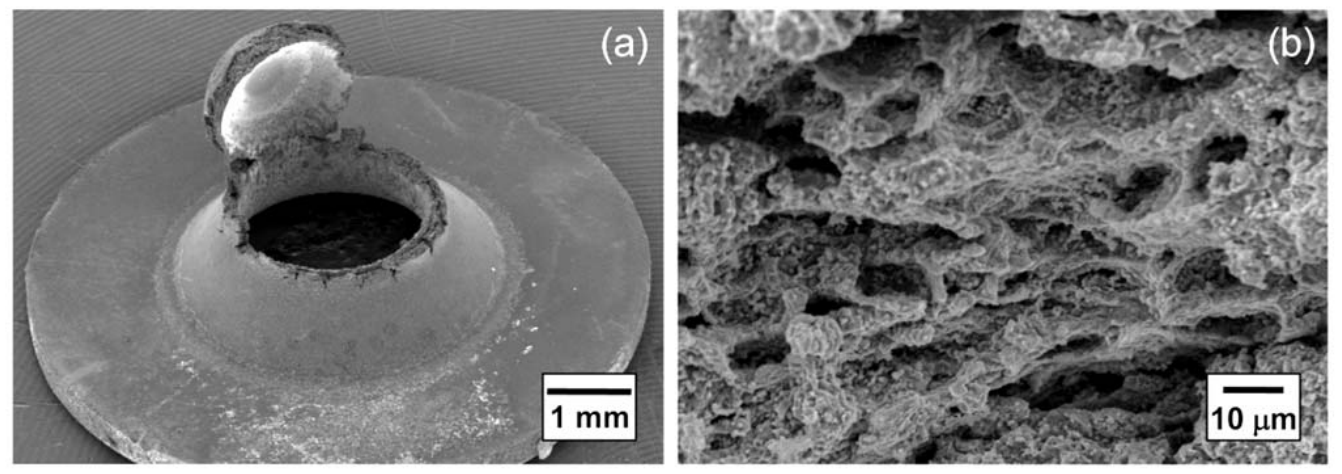

Fig. 6 a) SP creep specimen after rupture and b) fracture surface depicting ductile transgranular mode of fracture in $\mathrm{HN} 9 \mathrm{~L}$ after creep test at $725^{\circ} \mathrm{C}$ at $140 \mathrm{~N}$.

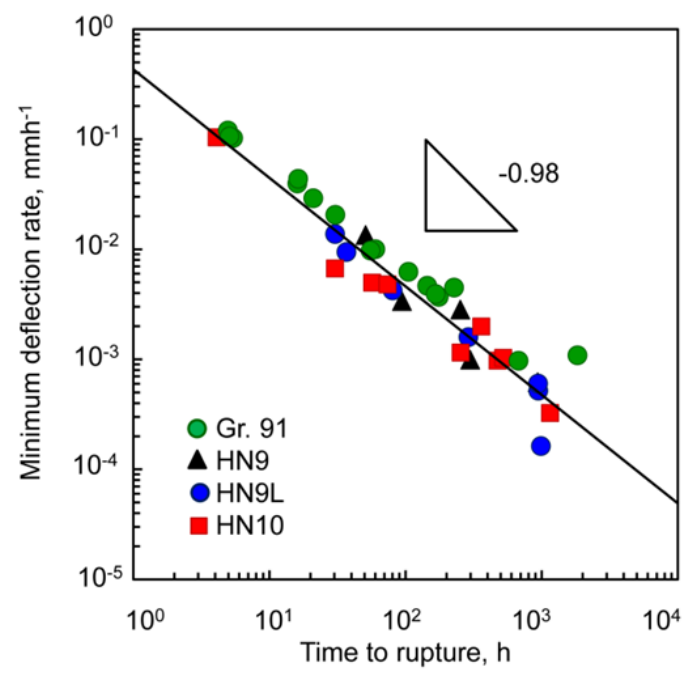

Fig. 7 Relationship between minimum deflection rate and time to rupture obeying MonkmanGrant relationship in Gr.91 and high nitrogen ferritic steels. 


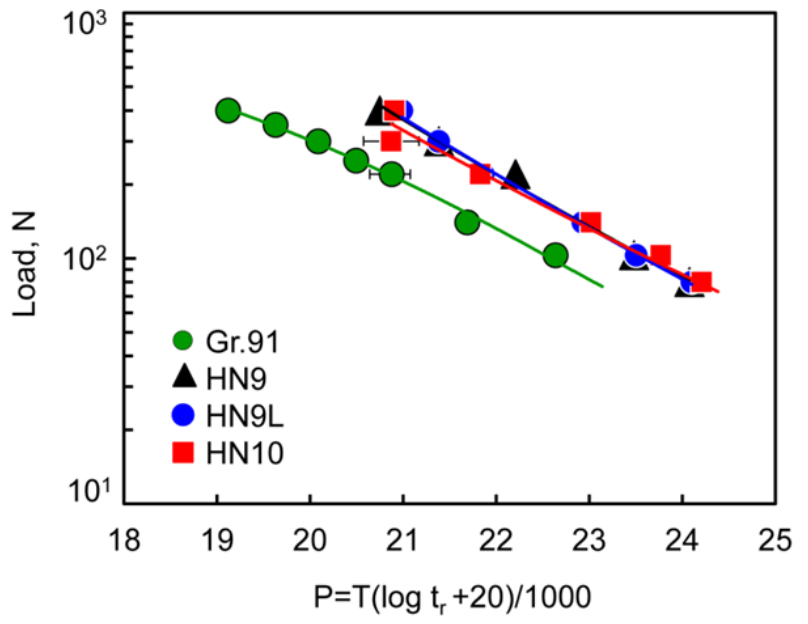

Fig. 8 Creep rupture strength of high nitrogen steels in comparison with Gr.91 steel.

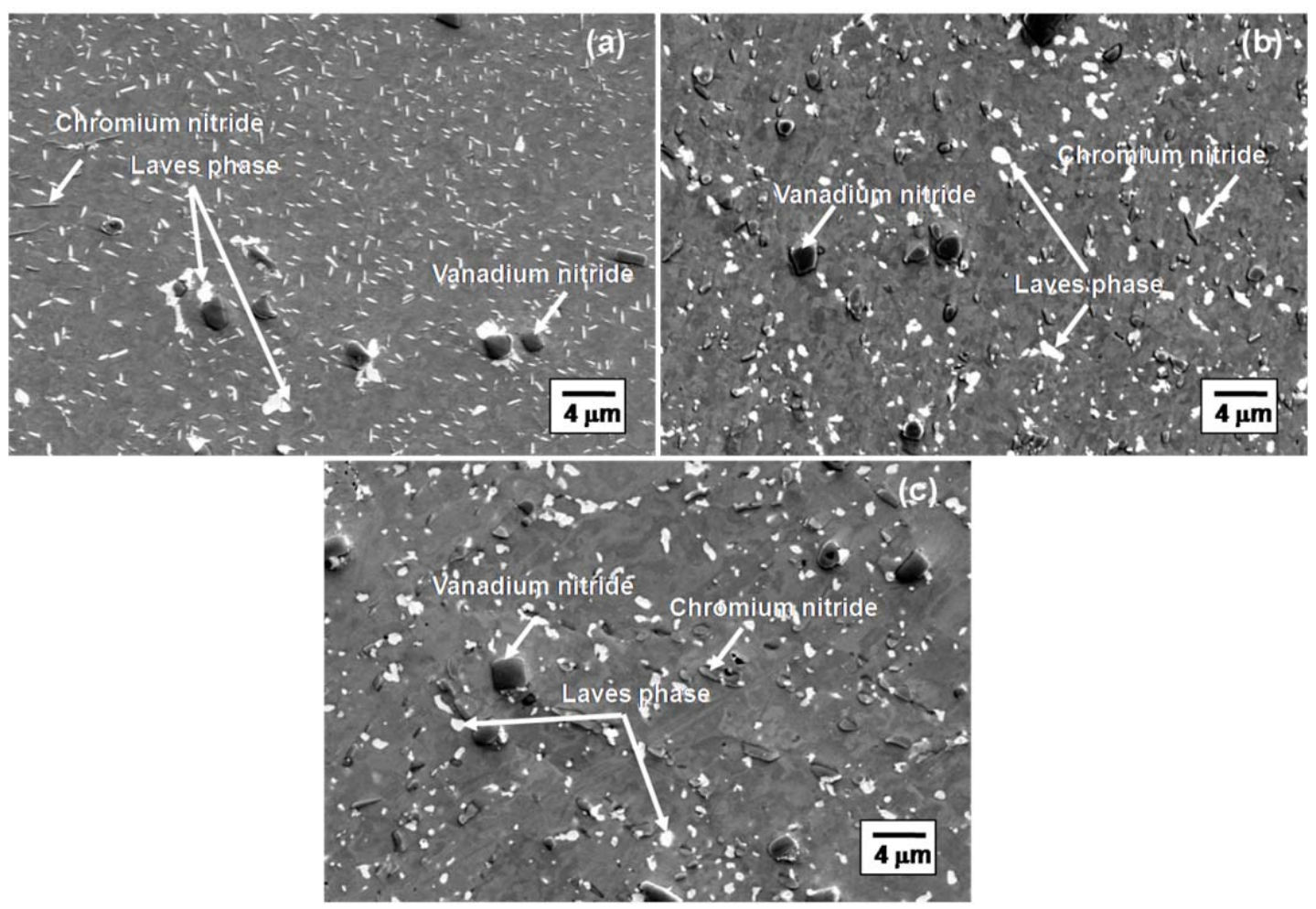

Fig. 9 Back-scattered electron micrographs depicting microstructures after creep test, a) HN9 up to $933 \mathrm{~h}$ at $775^{\circ} \mathrm{C}$ at $80 \mathrm{~N}$, b) $\mathrm{HN} 9 \mathrm{~L}$ up to $987 \mathrm{~h}$ at $775^{\circ} \mathrm{C}$ at $80 \mathrm{~N}$ and c) $\mathrm{HN} 10$ up to1152 h at $725^{\circ} \mathrm{C}$ at $140 \mathrm{~N}$. 

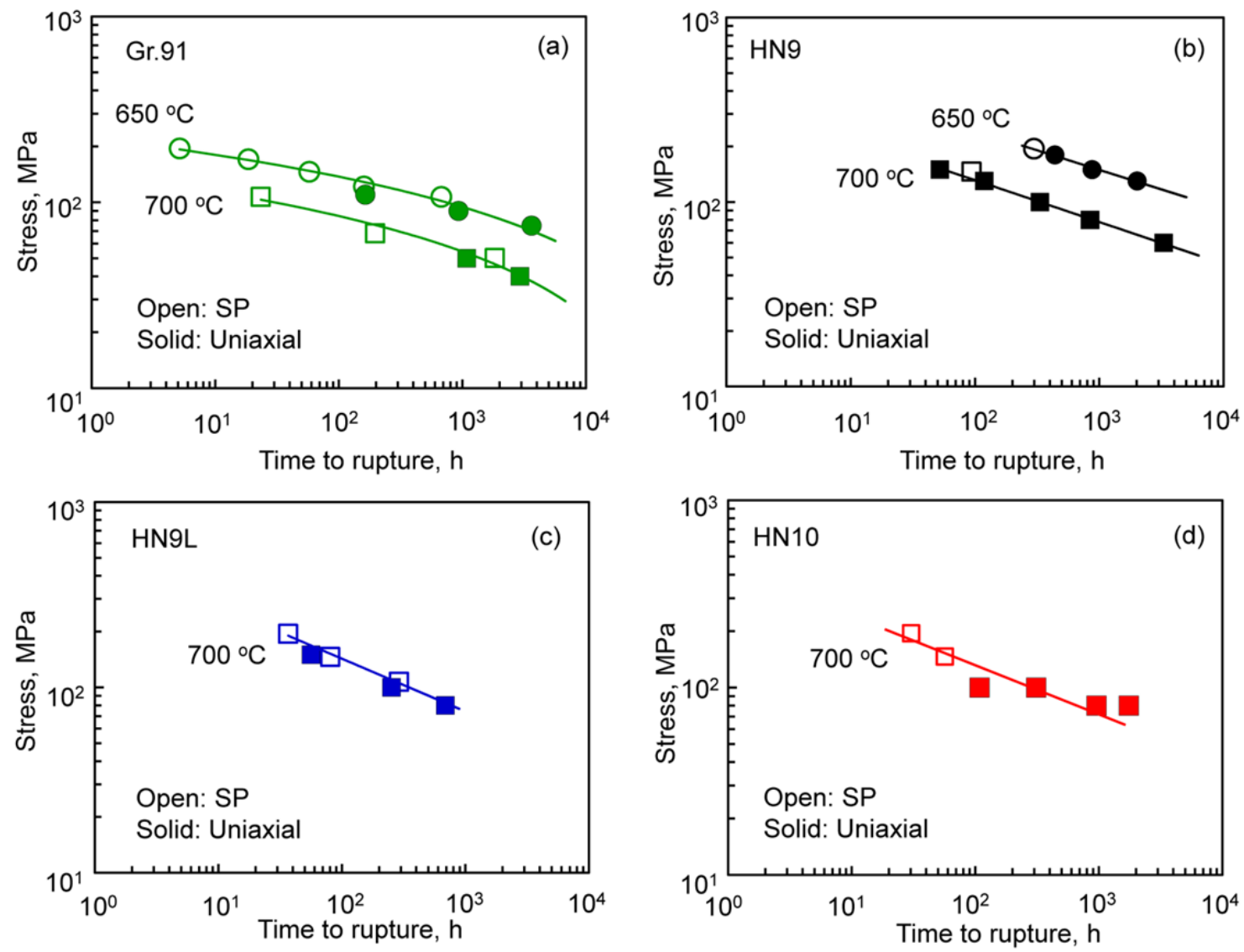

Fig. 10 Stress versus time to rupture curves of a) Gr.91, b) HN9, c) HN9L and d) HN10 steels depicting correlation between $\mathrm{SP}(\alpha=2.05)$ and uniaxial creep rupture test results. 

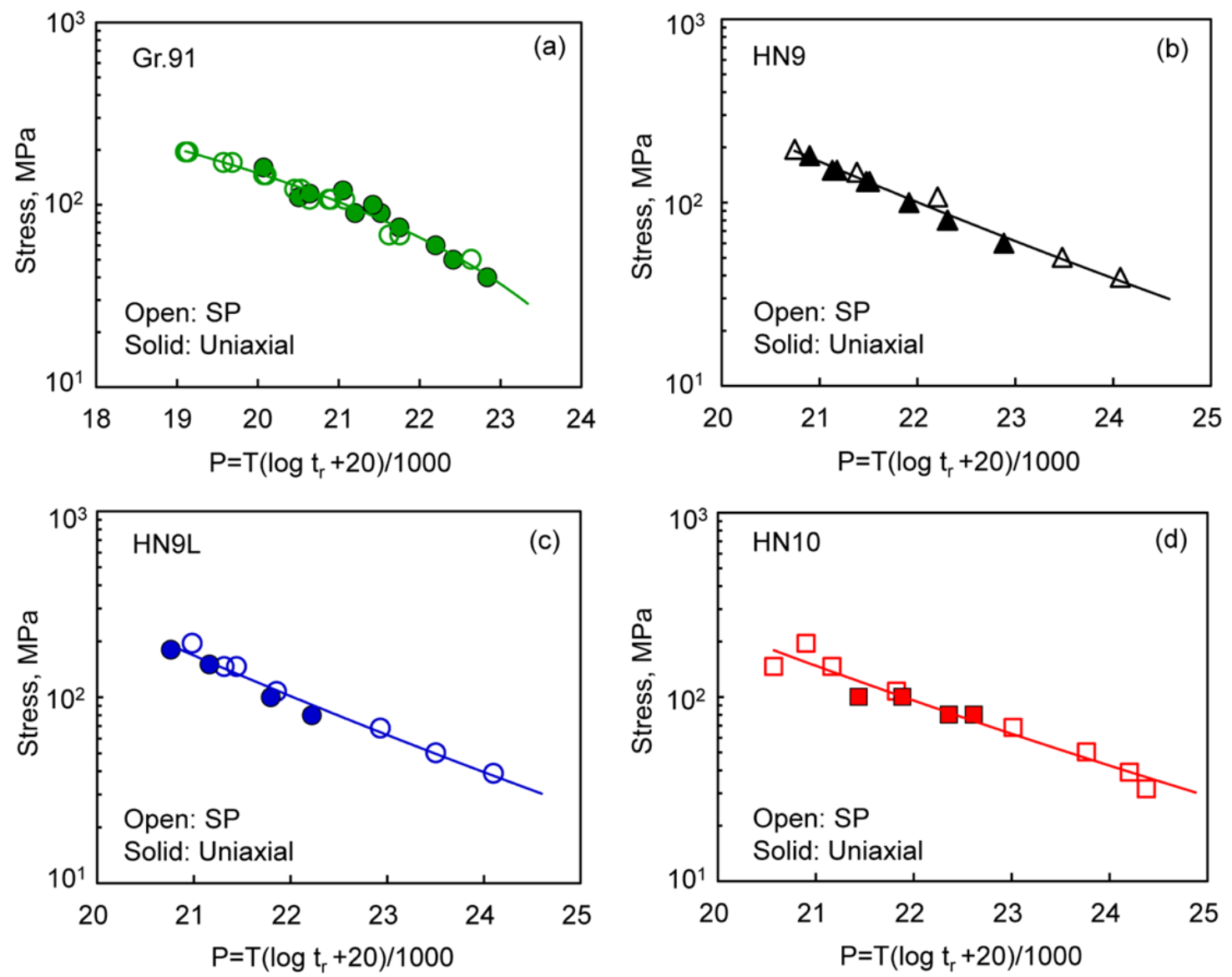

Fig. 11 Correlation between SP and uniaxial creep rupture test results for a) Gr.91, b) HN9, c) HN9L and d) HN10 steels, using $\alpha=2.05$. 